\title{
Hidrocele decorrente de hiperparasitismo em ovino
}

Beatriz Dantas Fernandes", Francisco Ermerson Ferreira Bezerra, Hermano Manoel Francisco Figueiredo Bezerra, Bismark Alves da Silva, Juliany Alves de Souza, Mariely Pessoa de Brito, Jéssica Monique dos Santos Lima, Sheila Nogueira Ribeiro Knupp,Ana Valéria Mello de Souza Marques, Luis Eduardo Pereira de Andrade Ferreira

Instituto Federal da Paraíba(IFPB), Sousa, PB, Brasil

*Autor correspondente

e-mail: beatriz_dfernandes@hotmail.com

\section{Resumo}

A haemoncose é comumente diagnosticada no rebanho ovino/caprino nacional, tendo como agente etiológico o helminto gastrointestinal Haemoncus contortus. Este parasita é adquirido pelo animal através da cavidade oral, geralmente durante o pastoreio em local contaminado. Após ser ingerido, o $\mathrm{H}$. contortus migra até o abomaso; neste órgão, as larvas na fase L3 penetram a mucosa e transformam-se em L4, podendo permanecer neste estágio enquanto não há condições favoráveis para seu desenvolvimento. Quando a larva passa para o estágio de L5, cada helminto consome cerca de $0,05 \mathrm{ml}$ de sangue/dia. Esta hematofagia pode acarretar o surgimento de diversos sinais clínicos quando o parasitismo é intenso. Dentre os sinais mais frequentes observados, destacam-se palidez das mucosas (anemia) e edema (hipoproteinemia), sendo mais comum o edema submandibular e a ascite. Este trabalho tem como objetivo relatar um caso de hidrocele decorrente de haemoncose, em um ovino proveniente da cidade de Sousa, no estado da Paraíba. 0 animal foi atendido no Hospital Veterinário do Instituto Federal da Paraíba, Campus Sousa - IFPB, onde durante a anamnese, o proprietário informou que o animal apresentava apatia, oligúria e oligoquesia há seis dias. Ao exame clínico, observou-se mucosas hipocoradas, retração ocular, exsicose de 5\%, secreção serosa nas narinas, taquipnéia, dispnéia inspiratória, roce pulmonar, taquicardia, ascite e hidrocele. Em seguida foram solicitados exames complementares (hemograma e parasitológico de fezes). No hemograma constatou-se um baixo volume globular (2[a]\%) apresentando ainda leucocitose ([a]9.[a]00/ $\mu \mathrm{L}$ ), além de neutrofilia, $68 \%$ de segmentados ([a]2.988/ $\mu \mathrm{L})$, e hipoproteinemia $(3.8 \mathrm{~g} / \mathrm{dL})$. Na técnica Gordon \& Whitlock, observou-se 4.300 ovos por grama de fezes. Após a avaliação clínica e os resultados dos exames, foi instituído um tratamento com antihelmíntico (cloridato de levamisol - $2.5 \mathrm{~mL}$ via oral), aplicação de soro glicosado (250mL intravenoso) e aplicação de cobalzam (5mL intramuscular); além disso, foi realizada abdominocentese com o intuito de diminuir a pressão que o líquido exercia no diafragma. Apesar do tratamento instituído, o animal 
teve leve melhora do quadro respiratório e cardíaco apenas após a abdominocentese, regredindo após aproximadamente uma hora de internação, ocorrendo o óbito logo em seguida. 0 animal foi encaminhado à necropsia, na qual houve a confirmação do quadro da haemoncose pela intensa presença do parasito no abomaso. Ainda que a haemoncose seja uma patologia muito comum no nordeste do Brasil, normalmente não há desenvolvimento de edema escrotal ou mesmo ascite em grandes proporções, como observados no caso relatado, sendo esta responsável por aumentar a concentração de hemácias, elevando o volume globular e dificultando o diagnóstico. Além disso, a ascite causou comprometimento cardiorrespiratório significativo devido à pressão exercida sobre o diafragma e sobre os grandes vasos (aorta abdominal e veia cava), o que pode ter favorecido o desenvolvimento de hidrocele. 